\title{
Methane fluxes show consistent temperature dependence across microbial to ecosystem scales
}

\author{
Gabriel Yvon-Durocher, Andrew P. Allen, David Bastviken, Ralf Conrad, Cristian Gudasz, \\ Annick St-Pierre, Nguyen Thanh-Duc and Paul A. del Giorgio
}

\section{Linköping University Post Print}

\section{Tweet}

N.B.: When citing this work, cite the original article.

Original Publication:

Gabriel Yvon-Durocher, Andrew P. Allen, David Bastviken, Ralf Conrad, Cristian Gudasz, Annick St-Pierre, Nguyen Thanh-Duc and Paul A. del Giorgio, Methane fluxes show consistent temperature dependence across microbial to ecosystem scales, 2014, Nature, (507), 7493, 488-491. http://dx.doi.org/10.1038/nature13164

Copyright: Nature Publishing Group

http://www.nature.com/

Postprint available at: Linköping University Electronic Press http://urn.kb.se/resolve?urn=urn:nbn:se:liu:diva-106286 
1 Temperature dependence of methane emissions: consistent scaling from methanogenesis to ecosystem-level fluxes

4 Gabriel Yvon-Durocher ${ }^{1 *}$, Andrew P. Allen ${ }^{2}$, David Bastviken ${ }^{3}$, Ralf Conrad ${ }^{4}$, 5 Cristian Gudasz ${ }^{5}$, Annick St-Pierre ${ }^{6}$, Nguyen Thanh-Duc ${ }^{7} \&$ Paul A. del Giorgio ${ }^{6}$

7 1. Environment and Sustainability Institute, University of Exeter, Penryn, Cornwall, TR10 9EZ. U.K.

8 2. Department of Biological Sciences, Macquarie University, Sydney, NSW 2109, Australia

9 3. Department of Thematic Studies - Water and Environmental Studies, Linköping University, SE-581

1083 Linköping, Sweden.

11 4. Max-Planck-Institute for Terrestrial Microbiology, Karl-von-Frisch-Str.10, 35043 Marburg,

12 Germany

13 5. Department of Ecology and Environmental Sciences, Umeå University, Linnaeus väg 6, SE-901 87

14 Umeå, Sweden. Current address: Department of Ecology and Evolutionary Biology, Princeton

15 University, Princeton, 106A Guyot Hall, NJ 08544, USA

16 6. Département des sciences biologiques, Université du Québec à Montréal, Montréal, Province of

17 Québec, H2X 3X8, Canada.

18 7. Earth Systems Research Center, Institute for the Study of Earth, Oceans, and Space; University of

19 New Hampshire, Durham, NH 03824, USA

20

$21{ }^{*}$ Correspondence to: Gabriel Yvon-Durocher (g.yvon-durocher@exeter.ac.uk), TEL:

$22 \quad 01326259481$

23

24 Words in abstract: 300

25 Words in main text: 1778

26 Figures: 3 
28 Methane $\left(\mathrm{CH}_{4}\right)$ is an important greenhouse gas because it has 25 times the global

29 warming potential of carbon dioxide $\left(\mathrm{CO}_{2}\right)$ by mass over a century ${ }^{1}$. Recent

30 calculations suggest that atmospheric $\mathrm{CH}_{4}$ emissions have been responsible for

31 approximately $20 \%$ of planet's warming since pre-industrial times ${ }^{2}$.

32 Understanding how $\mathrm{CH}_{4}$ emissions from ecosystems will respond to expected

33 increases in global temperature is therefore fundamental for predicting the

34 magnitude of feedbacks between the carbon cycle and climate change.

35 Methanogenesis is the terminal step in the remineralisation of organic matter

36 and is carried out by strictly anaerobic Archaea $^{3}$. Like most other enzymatically

37 mediated forms of metabolism, methanogenesis is temperature dependent ${ }^{4,5}$.

38 However, it is not yet known how this physiological response combines with

39 other biotic - e.g. methanotrophy ${ }^{6}$, substrate supply $^{3,7}$, microbial community

40 composition $^{8}$ - and abiotic - e.g. water-table depth ${ }^{9,10}$ - processes to determine

41 the temperature sensitivity of ecosystem-level $\mathrm{CH}_{4}$ emissions. Nor is it known

42 whether $\mathrm{CH}_{4}$ emissions at the ecosystem-level have a fundamentally different

43 temperature dependence than other key fluxes in the carbon cycle, such as

44 photosynthesis and respiration. Here we use meta-analyses to show that seasonal

45 variations in $\mathrm{CH}_{4}$ emissions from a wide range of ecosystems exhibit an average

46 temperature dependence similar to that of $\mathrm{CH}_{4}$ production derived from pure

47 cultures of methanogens and anaerobic sediment slurries. This average

48 temperature dependence ( 0.98 electron volts $(\mathrm{eV}))$, which corresponds to a 61-

49 fold increase between $0-30^{\circ} \mathrm{C}$, is considerably higher than previously observed

50 for respiration (approximately $0.65 \mathrm{eV}$ ) ${ }^{11}$ and photosynthesis (approximately 0.3

$51 \mathrm{eV})^{12}$. As a result, we show that both the emission of $\mathrm{CH}_{4}$ and the ratio of

$52 \mathrm{CH}_{4}: \mathrm{CO}_{2}$ emissions increase markedly with seasonal increases in temperature. 
53 Our findings suggest that global warming may have a large impact on the relative contributions of $\mathrm{CO}_{2}$ and $\mathrm{CH}_{4}$ to total greenhouse gas emissions from continental aquatic ecosystems, terrestrial wetlands and rice paddies.

Biogenic methane $\left(\mathrm{CH}_{4}\right)$ fluxes are a major component of global $\mathrm{CH}_{4}$ emissions, yet they are poorly constrained ${ }^{2,13,14}$. There are large uncertainties not only in the current magnitude of these fluxes, but also in the factors that regulate them ${ }^{2,13}$. In particular, there is substantial uncertainty in the parameterisation of the temperature dependence of natural $\mathrm{CH}_{4}$ emissions in process-based biogeochemistry models ${ }^{15-18}$, which greatly hinders our ability to predict the response of this key component of the carbon cycle to global warming. For example, temperature sensitivities for ecosystem-level $\mathrm{CH}_{4}$ emissions have reported apparent activation energies that range from 0.2 to $2.5 \mathrm{eV}^{6,19-21}\left(1 \mathrm{eV}=96 \mathrm{~kJ} \mathrm{~mol}^{-1}\right)$. In a bid to reduce this uncertainty, which is fundamental to improving projections of future carbon cycle-climate change feedbacks ${ }^{15-18}$, we quantified variation in the temperature dependence of $\mathrm{CH}_{4}$ fluxes for three different types of experiments - i.e. methanogenic cultures, anaerobic sediment slurries, and seasonal field surveys of $\mathrm{CH}_{4}$ emissions - that correspond to three distinct levels of biological organisation - i.e. population, community, and ecosystem, respectively. In particular, we assess whether ecosystem-level $\mathrm{CH}_{4}$ emissions exhibit a temperature dependence similar to that of the underlying methanogenic process, and quantify the magnitude of between site deviations from this physiological response. To do this, we first establish the magnitude and variability of the temperature dependence of key metabolic rate processes (i.e. methanogenesis, growth) for populations of methanogens in culture, as well as the temperature dependence of $\mathrm{CH}_{4}$ production for anaerobic microbial communities in slurries. We then assess whether these temperature dependencies 
differ from those observed in an ecosystem-level analysis of the seasonal temperature dependence of natural $\mathrm{CH}_{4}$ emissions from aquatic, wetland and rice paddy ecosystems (see S1 of the Supplementary Information). Our ecosystem analysis includes both new and previously published data that together encompass 1553 paired estimates of $\mathrm{CH}_{4}$ emission and temperature taken from 126 field sites.

To directly characterise the physiological temperature dependence of key metabolic rate processes for methanogens, we compiled data on rates of methanogenesis and growth from laboratory cultures of methanogen populations as well as rates of $\mathrm{CH}_{4}$ production from microbial communities in anaerobic sediment slurries (see S1 of the Supplementary Information). We then separately fit the data compiled for each type of experiment to a Boltzmann-Arrhenius function, which characterises the exponential relationship between metabolic rate and temperature assuming a single enzyme catalysed reaction is rate-limiting ${ }^{22}$, using a linear mixedeffects model (see S2 of the Supplementary Information) of the form ${ }^{23}$

$$
\ln F_{i}(T)=\left(\overline{E_{M}}+\varepsilon_{E_{M}, i}\right)\left(1 / k T_{C}-1 / k T\right)+\left(\overline{\ln F\left(T_{C}\right)}+\varepsilon_{F, i}\right)
$$

where $\ln F_{i}(T)$ is the natural logarithm of the measured rate of $\mathrm{CH}_{4}$ production or growth rate at absolute temperature, $T(\mathrm{~K})$, for some arbitrary experimental unit, $i$. In this expression, each experimental unit, $i$, corresponds to a distinct strain of methanogen (culture analysis) or sediment community (slurry analysis) that has been subjected to a range of temperatures. The parameter $\overline{E_{M}}\left(\right.$ in $\left.\mathrm{eV} ; 1 \mathrm{eV}=96 \mathrm{~kJ} \mathrm{~mol}^{-1}\right)$ corresponds to an average among experimental units for the apparent activation energy, which characterises the temperature sensitivity of $F_{i}(T)$, and $k$ is the Boltzmann constant $\left(8.62 \times 10^{-5} \mathrm{eV} \mathrm{K}^{-1}\right)$. We centred the temperature data using the mean temperature, $T_{C}$, across experimental units, so that $\overline{\ln F\left(T_{C}\right)}$ corresponds to an 
102

103

104

105

106

107

108

112 therefore have a similar temperature sensitivity (Fig. 1a; $\overline{E_{M}}=1.10 \mathrm{eV}, 95 \%$

113 confidence interval: $0.93-1.27 \mathrm{eV}$ ). The community-level analysis of $\mathrm{CH}_{4}$

114 production rates in anaerobic slurries yields a similar value for $\overline{E_{M}}(0.93 \mathrm{eV}, 95 \%$

115 confidence interval: $0.82-1.03 \mathrm{eV}$ ), indicating that the temperature dependence of

$116 \mathrm{CH}_{4}$ production at the community level largely reflects the kinetics of the

117 physiological processes generating this flux. More detailed analyses indicate that the

118 estimates of $\overline{E_{M}}$ for sediment slurries obtained from three broadly defined ecosystem

119 types (i.e. aquatic, wetlands, rice paddies; see S1 of the Supplementary Information

120 for details of the data) are statistically indistinguishable (likelihood ratio test: $\chi^{2}=$

121 1.62, d.f. $=2, P=0.44)$. Consistent with our expectations, $E_{M}$ does vary between

122 experimental units, $i$, as reflected by the magnitude of the standard deviation of the

123 random effect on the slope of the Arrhenius model, $\varepsilon_{E_{M}, i}$, in both analyses (see Table 
To explore how the temperature dependence of methanogenic populations and communities, compare to that of natural ecosystem-level $\mathrm{CH}_{4}$ emissions, we fit equation (1) - here experimental units, $i$, correspond to sites - to a database of 1553 measurements of $\mathrm{CH}_{4}$ emission and temperature, measured seasonally for 126 field sites that span the globe and encompass three distinct ecosystem types (aquatic, wetlands, rice paddies - see S1 of the Supplementary Information for definitions). Analyses reveal that estimates of $\overline{E_{M}}$ are statistically indistinguishable among ecosystem types (likelihood ratio test: $\chi^{2}=4.97$, d.f. $=2, P=0.10$ ), and therefore that the average temperature dependence of $\mathrm{CH}_{4}$ emissions from diverse ecosystem types can be characterised by a common apparent activation energy $\left(\overline{E_{M}}=0.98 \mathrm{eV}\right.$; 95\% confidence interval: $0.88-1.08$; see Fig. 2). This average temperature dependence is strikingly similar to that observed for methane production in cultures and sediment slurries (Fig. 1), which is remarkable given the multitude of processes e.g. methanotrophy ${ }^{6}$, water-table depth ${ }^{9,10}$, substrate supply ${ }^{7}$, community composition ${ }^{8}$ - that may confound the temperature dependence of $\mathrm{CH}_{4}$ emissions over a seasonal cycle at the ecosystem-level. Our analysis is broadly consistent with the hypothesis that the seasonal temperature dependence of $\mathrm{CH}_{4}$ emissions at the ecosystem-level largely reflects the kinetics of the methanogenic process generating this flux (see S4 for further discussion of the potential mechanisms constraining the scaling of the temperature dependence of $\mathrm{CH}_{4}$ emissions). Importantly, the average apparent activation energy we report here for the seasonal temperature dependence of ecosystem-level $\mathrm{CH}_{4}$ emissions $\left(\overline{E_{M}}=0.98 \mathrm{eV}\right)$ is considerably higher than that reported previously for $\mathrm{CO}_{2}$ fluxes attributable to respiration $(\sim 0.65 \mathrm{eV})^{11}$, which could have important implications for the effect of global warming on the balance of $\mathrm{CH}_{4}$ and $\mathrm{CO}_{2}$ emissions from ecosystems ${ }^{24}$. 
Given the average seasonal temperature dependencies of $\mathrm{CH}_{4}$ emissions

151 reported here $\left(\overline{E_{M}}=0.98 \mathrm{eV}\right)$, and that previously documented for respiration $(\sim 0.65$

$152 \mathrm{eV})^{11}$, we expected the ratio of $\mathrm{CH}_{4}$ to $\mathrm{CO}_{2}$ emission to increase, on average, with

153 seasonal increases temperature across a collection of sites (see S3 of the

154 Supplementary Information). While the temperature dependence of this ratio is not

155 expected to adhere to a Boltzmann-Arrhenius relationship, we can approximate it

156 using an expression of the form (see S3 of the Supplementary Information for a

157 derivation of Eq. 2)

$158 \ln Q_{i}(T)=\left(\overline{E_{M: C}}+\varepsilon_{E_{M: C}, i}\right)\left(1 / k T_{C}-1 / k T\right)+\left(\overline{\ln Q\left(T_{C}\right)}+\varepsilon_{Q, i}\right)$

159 where $Q_{i}(T)$ is the ratio of $\mathrm{CH}_{4}$ to $\mathrm{CO}_{2}$ emissions for site $i$ at temperature $T, \overline{E_{M: C}}$

160 and $\overline{\ln Q\left(T_{C}\right)}$ are averages across sites for the temperature dependence of this ratio and

161 the magnitude of the ratio at temperature $T_{C}$, and $\varepsilon_{E_{M: C}, i}$ and $\varepsilon_{Q, i}$ are random-effects

162 terms used to represent site-level deviations from these respective averages.

163 To test this prediction, we analyse ecosystem-level data for the subset of

164 studies in our compilation that report simultaneous measurements of ecosystem-level

165 fluxes of $\mathrm{CH}_{4}$ and $\mathrm{CO}_{2}$, enabling us to calculate the efflux ratio of these greenhouse

166 gases in response to seasonal variation in temperature. This dataset comprises 177

167 estimates from 38 field sites. In exactly the same way as for the analyses of $\mathrm{CH}_{4}$

168 emissions, we fit a linear mixed effects model using the Boltzmann-Arrhenius

169 function to the natural logarithm of the $\mathrm{CH}_{4}: \mathrm{CO}_{2}$ flux data (see Eq. 2). As predicted,

170 this ratio increases with increasing temperature for the majority of the field sites (35

171 of 38), yielding average temperature dependence across sites of $\overline{E_{M: C}}=0.71 \mathrm{eV}(95 \%$

172 confidence interval: $0.46-0.97$; see Fig. 3). This finding suggests that, on average,

173 the relative contribution of methane to total greenhouse gas emissions from aquatic 
174 ecosystems increases with seasonal increases in temperature due to the differences in

175 the biochemical kinetics of methanogenesis, respiration and photosynthesis.

Our analyses demonstrate that the average apparent activation energy of $\mathrm{CH}_{4}$

177 emissions across a wide range of ecosystems scales consistently with that of

178 populations of methanogens in culture, and laboratory incubations of microbial

179 communities. Moreover, this temperature dependence is much higher than that of both 180 respiration ${ }^{11}$ and photosynthesis ${ }^{12}$, resulting in a greater relative contribution of $\mathrm{CH}_{4}$

181 to total $\mathrm{C}$ emissions from aquatic ecosystems at higher temperatures. While this

182 scaling of the temperature dependence of $\mathrm{CH}_{4}$ fluxes across levels of biological

183 organisation is remarkable, our results also emphasise that temperature is not the only

184 variable that controls $\mathrm{CH}_{4}$ emissions. Indeed, the substantial site-to-site variation we

185 report for the temperature dependence of ecosystem-level $\mathrm{CH}_{4}$ emissions

186 (characterized by $\varepsilon_{E_{M}, i}$ in our mixed-effects model; see also Fig. 2b \& Table 1),

187 highlights the importance of other variables in driving deviations from the underlying

188 physiological response. It is also important to note, that the average within-site

189 apparent activation energy we report here for $\mathrm{CH}_{4}$ emissions $\left(\overline{E_{M}}=0.98 \mathrm{eV}\right)$ does not

190 hold for the temperature response derived from geographic variation in average $\mathrm{CH}_{4}$

191 emissions and temperature across sites. For example, average site temperature is a

192 poor predictor of spatial variation in average emissions for each ecosystem type (see

193 Extended Data Figures $1 \&$ 2), suggesting that other biotic - e.g. methanotrophy ${ }^{6}$,

194 substrate supply ${ }^{3,7}$, microbial community composition ${ }^{8}-$ and abiotic - e.g. water-table

195 depth ${ }^{9,10}$ - variables, besides temperature, may be more important for driving

196 differences in total $\mathrm{CH}_{4}$ emissions among ecosystems.

197 Overall, our findings provide a robust basis for refining parameterisation of

198 the temperature sensitivity of $\mathrm{CH}_{4}$ fluxes in global coupled climate-carbon cycle 
models, a factor that until now yielded significant uncertainty in these models ${ }^{15}$. Furthermore, the observation of a general increase in the $\mathrm{CH}_{4}: \mathrm{CO}_{2}$ ratio with increasing temperature, driven by the high temperature sensitivity of $\mathrm{CH}_{4}$ production, has important implications for the magnitude of future positive feedbacks between global warming and the carbon cycle given the relative potency of $\mathrm{CH}_{4}$ compared to $\mathrm{CO}_{2}$ as a greenhouse gas ${ }^{2,13}$. In fact, a recent sensitivity analysis of the temperature dependence of $\mathrm{CH}_{4}$ production in CLM4Me ${ }^{16}$, a process-based wetland biogeochemistry model embedded within the land surface component of an Earth system model, demonstrates that a $\mathrm{Q}_{10}$ value of 4 , equivalent to the activation energies we identify ( $\overline{E_{M}} \approx 1.0 \mathrm{eV}$ ), would result in an $50 \%$ increase in high latitude $\mathrm{CH}_{4}$ emissions over the $21^{\text {st }}$ Century, relative to the model's baseline $\mathrm{Q}_{10}$ of 2 at $20^{\circ} \mathrm{C}$ $\left(\overline{E_{M}} \approx 0.5 \mathrm{eV}\right)$. Our analyses give strong evidence to support temperature sensitivities for methanogenesis and $\mathrm{CH}_{4}$ emissions that are substantially higher than other key fluxes in the carbon cycle, like heterotrophic respiration and photosynthesis, and suggest that current predictions of carbon cycle-climate change feedbacks ${ }^{25}$, which fail to account for these differences, may be significantly underestimated.

\section{References}

1. Forster, P. et al., Changes in Atmospheric Constituents and in Radiative Forcing. In: Climate change 2007: The physical science basis. Contribution of Working Group I to the Fourth Assessment Report of the Intergovernmental Panel on Climate Change. Eds: Solomon, S; Qin, D; Manning, M; Chen, Z; Marquis, M; Averyt, KB; Tignor, M; Miller, HL. Cambridge University Press. (2007).

2. Kirschke, S. et al. Three decades of global methane sources and sinks. Nature 
Geosci 6, 813-823 (2013).

225

226

227

228

229

230

231

232

233

234

235

236

3. Thauer, R. K., Kaster, A.-K., Seedorf, H., Buckel, W. \& Hedderich, R. Methanogenic archaea: ecologically relevant differences in energy conservation. Nature Reviews Microbiology 6, 579-591 (2008).

4. Westermann, P., Ahring, B. K. \& Mah, R. A. Temperature compensation in Methanosrcina barkeri. Applied and Environmental Microbiology 55, 1262 1266 (1989).

5. Zinder, S. H., Anguish, T. \& Cardwell, S. C. Effects of temperature on methanogenesis in a thermophilic (58-degrees-C) anaerobic digester. Applied and Environmental Microbiology 47, 808-813 (1984).

6. Segers, R. Methane production and methane consumption: a review of processes underlying wetland methane fluxes. Biogeochemistry 41, 23-51 (1998).

7. Whiting, G. J. \& Chanton, J. P. Primary production control of methane emission from wetlands. Nature 364, 794-795 (1993).

8. Fey, A. \& Conrad, R. Effect of temperature on carbon and electron flow and on the archaeal community in methanogenic rice field soil. Applied and Environmental Microbiology 66, 4790-4799 (2000).

9. Moore, T. R., Roulet, N. T. \& Waddington, J. M. Uncertainty in predicting the effect of climatic change on the carbon cycling of Canadian peatlands. CLIMATIC CHANGE $\{\mathbf{4 0}\},\{229-245\}$ (1998).

10. Moore, T. R. \& Roulet, N. T. Methane flux: Water table relations in northern wetlands. Geophys. Res. Lett. 20, 587-590 (1993).

11. Yvon-Durocher, G. et al. Reconciling the temperature dependence of respiration across time scales and ecosystem types. Nature 487, 472-476 
12. Allen, A. P., Gillooly, J. F. \& Brown, J.H. Linking the global carbon cycle to individual metabolism. Functional Ecology 19, 202-213 (2005).

13. Bridgham, S. D., Cadillo-Quiroz, H., Keller, J. K. \& Zhuang, Q. Methane emissions from wetlands: biogeochemical, microbial, and modeling perspectives from local to global scales. Global Change Biology 19, 1325$1346(2013)$.

14. Bastviken, D., Tranvik, L. J., Downing, J. A., Crill, P. M. \& Enrich-Prast, A. Freshwater Methane Emissions Offset the Continental Carbon Sink. Science 331, 50 (2011).

15. Gedney, N. Climate feedback from wetland methane emissions. Geophys. Res. Lett. 31, (2004).

261 16. Riley, W. J. et al. Barriers to predicting changes in global terrestrial methane fluxes: analyses using CLM4Me, a methane biogeochemistry model integrated in CESM. Biogeosciences 8, 1925-1953 (2011).

264 17. Spahni, R. et al. Constraining global methane emissions and uptake by ecosystems. Biogeosciences 8, 1643-1665 (2011).

266 18. Wania, R., Ross, I. \& Prentice, I. C. Implementation and evaluation of a new methane model within a dynamic global vegetation model: LPJ-WHyMe v1.3.1. Geosci. Mod. Dev 3, 565-584 (2010).

19. Christensen, T. R. et al. Factors controlling large scale variations in methane

271 20. Crill, P. M. et al. Methane flux from Minnesota Peatlands. Global Biogeochem. Cycles 2, 371-384 (1988).

273 21. Walter, B. P. \& Heimann, M. A process-based, climate-sensitive model to 
derive methane emissions from natural wetlands: Application to five wetland sites, sensitivity to model parameters, and climate. Global Biogeochem. Cycles 14, 745-765 (2000).

22. Eyring, $\mathrm{H}$. The Activated Complex and the Absolute Rate of Chemical Reactions. Chem. Rev. 17, 65-77 (1935).

23. Zuur, A., Ieno, E., Walker, N. \& Saveliev, A. Mixed effects models and extensions in ecology with R. (Springer Verlag, 2009).

24. Yvon-Durocher, G., Montoya, J. M., Woodward, G., Jones, J. I. \& Trimmer, M. Warming increases the proportion of primary production emitted as methane from freshwater mesocosms. Global Change Biology 17, 1225-1234 (2011).

25. Melton, J. R. et al. Present state of global wetland extent and wetland methane modelling: conclusions from a model inter-comparison project (WETCHIMP). Biogeosciences 10, 753-788 (2013).

Supplementary Information is linked to the online version of the paper at www.nature.com/nature.

Acknowledgements. We thank Mark Trimmer for early discussions that inspired much of this work.

Author contributions. GY-D, DB \& CG had initial discussions. GY-D conceived the study, analysed the data, and wrote the first draft of the manuscript. DB, PdG, CG, NT-D, RC \& AS contributed original data. APA wrote the theory for the $\mathrm{CH}_{4}: \mathrm{CO}_{2}$ temperature dependence. All authors contributed to revisions of the manuscript. 
299

300 Author information. Reprints and permissions are available at

301 www.nature.com/reprints. Correspondence and requests for materials should be sent 302 to g.yvon-durocher@exeter.ac.uk. 
Table 1| Estimates of the parameters used to characterise the temperature dependence of $\mathrm{CH}_{4}$ flux or the $\mathrm{CH}_{4} \mathrm{CO}_{2}$ efflux ratio. The standard deviations (s.d.) of site or experimental unit-specific estimates for $\varepsilon_{E_{M}, i}$ (equation 1) were significantly $>0$ for each of the analyses $(P<0.05)$, indicating differences among sites or experimental units in apparent activation energies. The standard deviations of site or experimental unit-specific estimates for $\varepsilon_{F, i}$ (equation 1) were significantly $>0$ in all analyses $(P<$ 0.001), indicating differences among sites or experimental units in $\mathrm{CH}_{4}$ flux or the $\mathrm{CO}_{2}: \mathrm{CH}_{4}$ efflux ratio at the average temperature.

313

\begin{tabular}{|c|c|c|c|}
\hline Flux Type & $\overline{E_{M}}(95 \% \mathrm{CI})$ & $\begin{array}{l}\text { s.d. } \\
\varepsilon_{E_{M}, i}\end{array}$ & $\begin{array}{l}\text { s.d. } \\
\varepsilon_{F, i}\end{array}$ \\
\hline \multicolumn{4}{|l|}{ Laboratory Studies } \\
\hline Pure culture methanogens & $1.10(0.93-1.27)$ & 0.42 & 2.28 \\
\hline Slurries $\mathrm{CH}_{4}$ production & $0.93(0.82-1.03)$ & 0.32 & 2.45 \\
\hline Whole Ecosystem $\mathrm{CH}_{4}$ Efflux & $0.98(0.88-1.08)$ & 0.36 & 2.16 \\
\hline $\mathrm{CO}_{2}: \mathrm{CH}_{4}$ ratio & $0.71(0.46-0.97)$ & 0.59 & 1.03 \\
\hline
\end{tabular}


Temperature $\left({ }^{\circ} \mathrm{C}\right)$
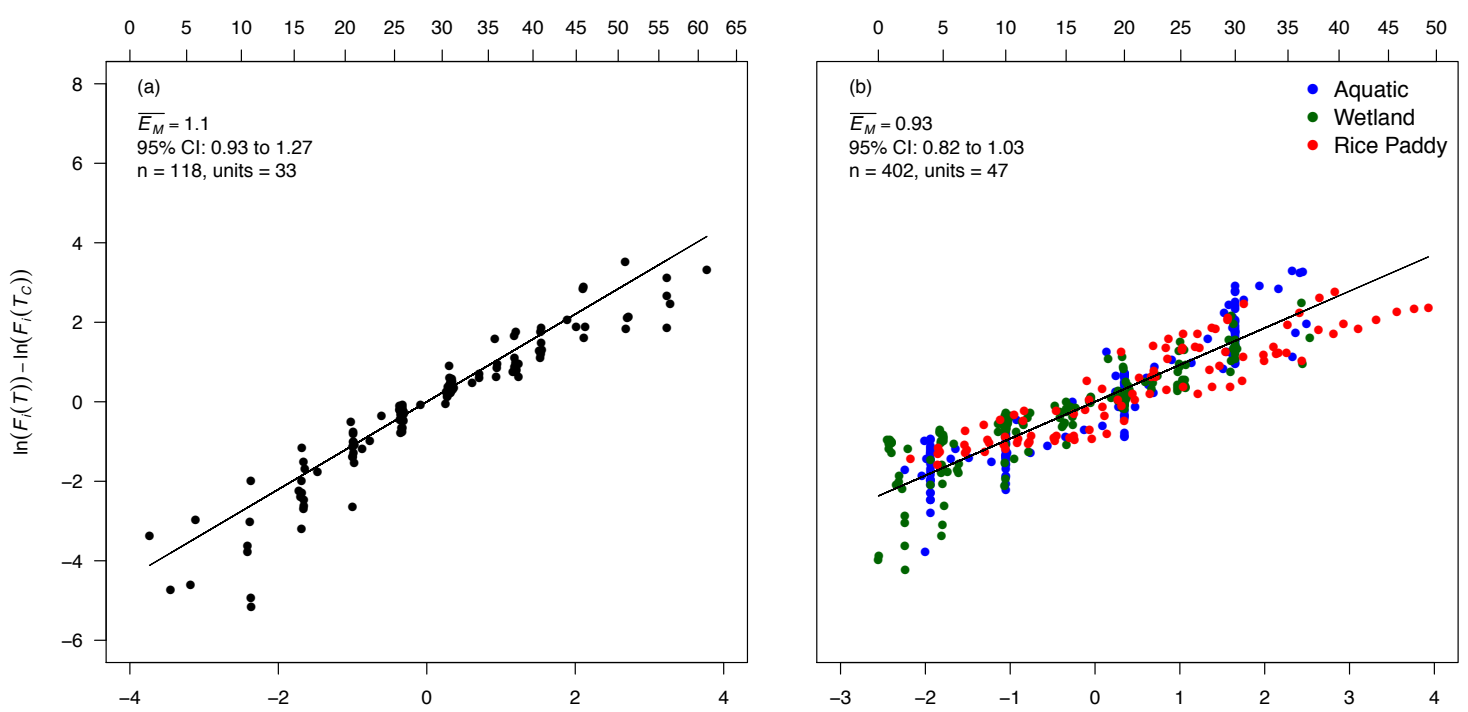

Standardised Temperature $\left(1 / k T_{C}-1 / k T(1 / \mathrm{eV})\right)$

Figure 1| The temperature dependence of $\mathrm{CH}_{\mathbf{4}}$ production. Analyses fitting the Boltzmann-Arrhenius function to rate data, reveal similar temperature dependencies for (a) pure cultures of methanogens, and (b) slurries of aquatic (red), wetland (green) and rice-paddy (red) sediment samples incubated at different constant temperatures in the laboratory. In (b), the temperature dependence of $\mathrm{CH}_{4}$ production is not significantly different among ecosystem types (see main text for details of statistics). In all plots, data have been standardised by subtracting from each measurement the estimated experiment-specific deviation from the average intercept predicted by the mixed-effects model. This standardisation was used for visualisation of the data only; raw values were used in the statistical analyses. 

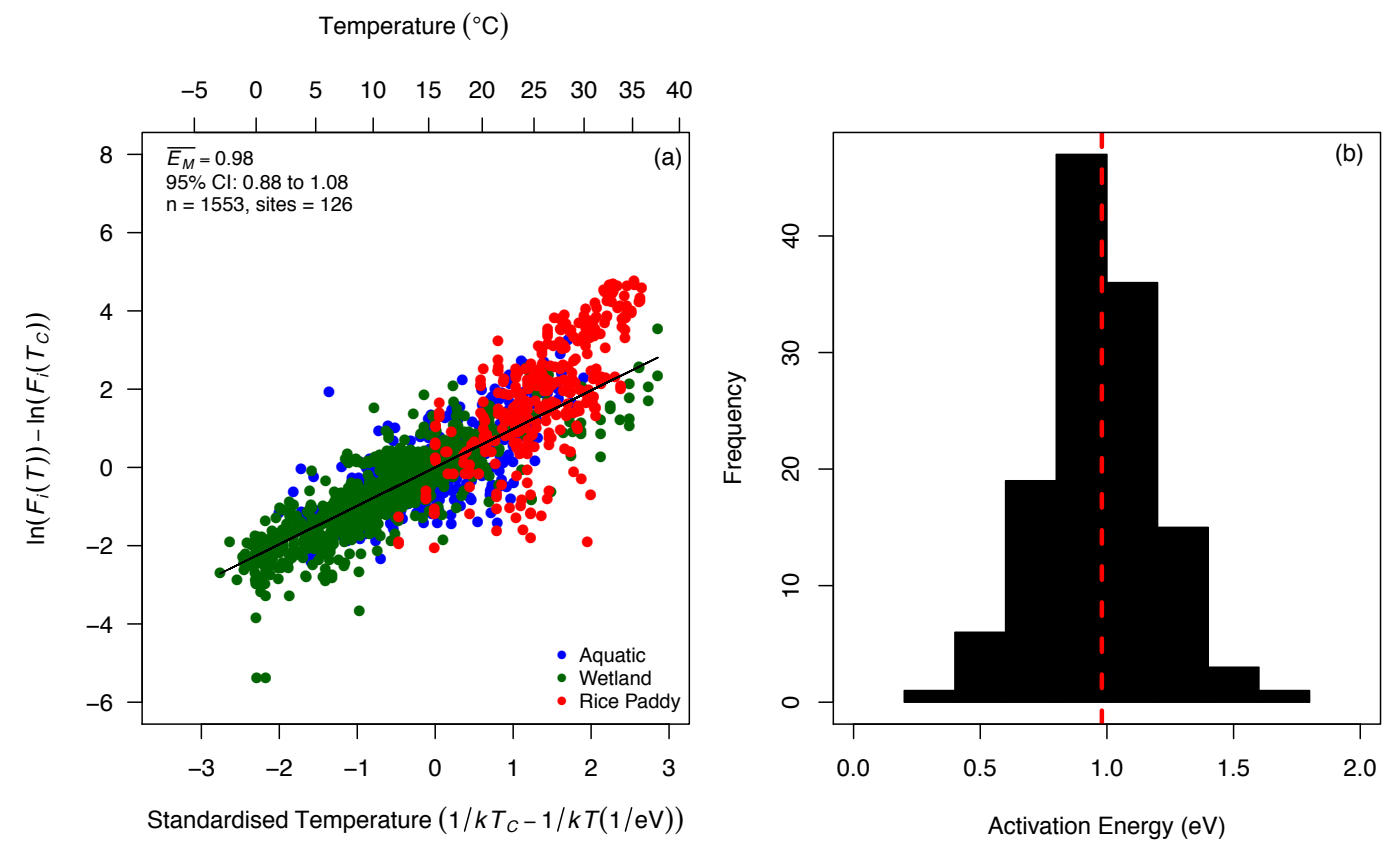

Figure 2| The temperature dependence of $\mathrm{CH}_{4}$ emissions at the ecosystem scale. Analysis reveals a consistent temperature dependence for the emission of $\mathrm{CH}_{4}$ from aquatic (red), wetland (green) and rice-paddy (red) ecosystems (a). Histogram of the site-level activation energies is also given (b), note that the majority of estimated apparent activation energies are very close to the average value derived from experiments using pure cultures and anaerobic sediment communities (see Fig. 1). The red dashed line in (b) corresponds to $\overline{E_{M}}=0.98 \mathrm{eV}$, estimated from the mixed effects model. In the Arrhenius plot, data have been standardised by subtracting from each measurement the estimated site-specific deviation from the average intercept predicted by the mixed-effects model. This standardisation was for visualisation of the data only; raw values were used in the statistical analyses. 

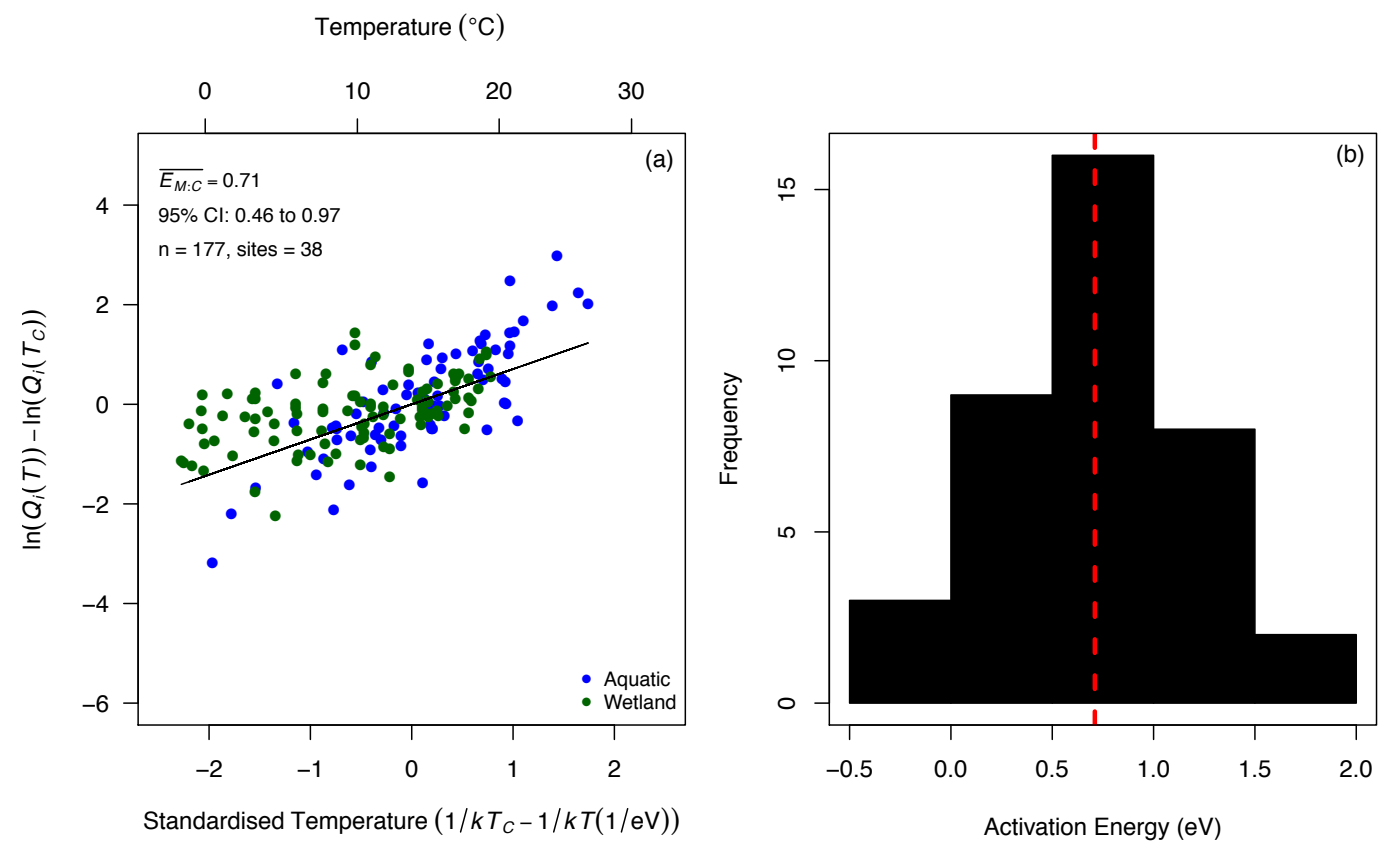

343

Figure 3| The temperature dependence of the $\mathrm{CH}_{4}: \mathrm{CO}_{2}$ emission ratio. Analyses reveal a high temperature dependence in the $\mathrm{CH}_{4}$ to $\mathrm{CO}_{2}$ emission ratio (a). A histogram of the site-level apparent activation energies is also given (b). The red dashed line in (b) corresponds to $\overline{E_{M: C}}=0.71 \mathrm{eV}$, estimated from the mixed effects model. As with Figs. $1 \& 2$, data for the Arrhenius plot have been standardised by subtracting from each measurement the estimated site-specific deviation from the average intercept predicted by the mixed-effects model. This standardisation was for visualisation of the data only; raw values were used in the statistical analyses. 